\title{
Cylindrical Induction Melter Modicon Control System
}

by

G. E. Weeks

Westinghouse Savannah River Company

Savannah River Site

Aiken, South Carolina 29808

DOE Contract No. DE-AC09-96SR18500

This paper was prepared in connection with work done under the above contract number with the U.S. Department of Energy. By acceptance of this paper, the publisher and/or recipient acknowledges the U. S. Government's right to retain a nonexclusive, royalty-free license in and to any copyright covering this paper, along with the right to reproduce and to authorize others to reproduce all or part of the copyrighted paper. 


\section{DISCLAIMER}

This report was prepared as an account of work sponsored by an agency of the United States Government. Neither the United States Government nor any agency thereof, nor any of their employees, makes any warranty, express or implied, or assumes any legal liability or responsibility for the accuracy, completeness, or usefulness of any information, apparatus, product, or process disclosed, or represents that its use would not infringe privately owned rights. Reference herein to any specific commercial product, process, or service by trade name, trademark, manufacturer, or otherwise does not necessarily constitute or imply its endorsement, recommendation, or favoring by the United States Government or any agency thereof. The views and opinions of authors expressed herein do not necessarily state or reflect those of the United States Government or any agency thereof.

This report has been reproduced directly from the best available copy.

Available to DOE and DOE contractors from the Office of Scientific and Technical Information, P.O. Box 62, Oak Ridge, TN 37831; prices available from (615) 576-8401.

Available to the public from the National Technical Information Service, U.S. Department of Commerce, 5285 Port Royal Road, Springfield, VA 22161. 


\section{DISCLAIMER}

Portions of this document may be illegible electronic image products. Images are produced from the best available original document. 


\section{Cylindrical Induction Melter Modicon Control System (U)}

AUTHOR:

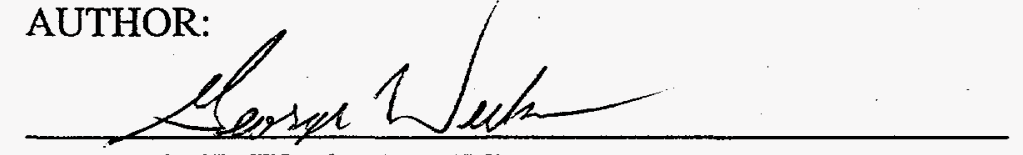

G. E. Weeks / SRTC

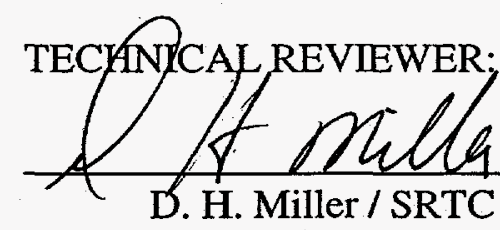

AUTHORIZED DERIVATIVE CLASSIFIER:

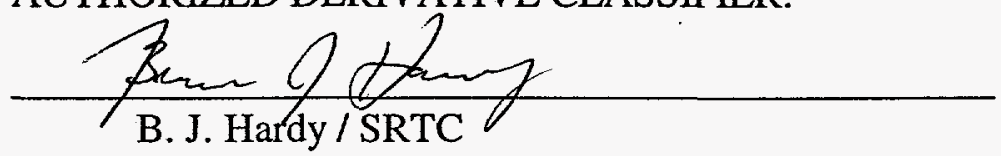




\section{Background}

In the last several years an extensive $R \& D$ program has been underway to develop a vitrification system to stabilize Americium (Am) and Curium (Cm) inventories at SRS. Extensive testing of four bushing melters and the drain tube test stand has led to the selection of induction heating as the method of choice to vitrify the $\mathrm{Am} / \mathrm{Cm}$ inventories. This report documents the Modicon control system designed for the 3 inch Cylindrical Induction Melter (CIM).

\section{Control System Overview}

The CIM control system is made up of 7 independent parts:

1. Factory Link supervisory control system

2. Modicon control system

3. Emergency shutdown cabinet

4. Ameritherm XP20 power unit

5. Ameritherm XP5 power unit

6. Control Room Enunciator Panel

7. Data Acquisition System

The figure in Appendix 1 shows data and control flow between the seven constituent parts. The Factory Link system communicates with the Modicon Programmable Logic Controller (PLC) to provide supervisory control and the man-machine interface. The Factory Link application also provides temperature ramping and manual temperature control for the CIM vessel and drain tube. The Modicon receives set-point information from the Factory Link system and process information from field instrumentation. With the exception of interlocks, it provides all control outputs to the Ameritherm power units. The Modicon system also provides alarm and interlock signals to the emergency shutdown cabinet. The emergency shutdown cabinet provides redundant temperature interlocks for four field selectable thermocouples and provides interlock signals to the Ameritherm power units. The emergency shutdown cabinet also provides alarm and interlock indications in the field and the control room.

\section{Discussion}

The design strategy for the CIM control system distributes control functions between each of the five control devices. This allows the system to continue to function in the event of a complete loss of the Factory Link system and to shutdown safely in the event of a loss of any of the other systems. Appendix 2 contains a list of alarms and interlocks that are trapped by the Modicon.

The Modicon ladder logic is divided into ten sections as described below: 
1. Networks 1-7 convert analog inputs from counts to engineering units.

2. Networks 8,9 constitute the watch dog timer.

3. Networks 10-12 selects the melter control thermocouple.

4. Networks 13-20 constitute the delta temperature alarm.

5. Networks 21-24 provide PID control for the Melter vessel temperature.

6. Network 25 controls the cooling air to the pour tip.

7. Network $26,72-75$ provides the system interlock.

8. Networks $27-68$ trap alarms and interlocks.

9. Networks 69-71 provide alarm tracking and activation.

10. Network 76 provides the data acquisition watchdog timer.

\section{$\underline{\text { Units Conversion }}$}

The Modicon is not capable of floating point calculations. To resolve this problem the decimal point is assumed to be between two holding registers and two register integer arithmetic is used. Each register can hold a four-digit number. Therefore, the largest number that can be represented in this format is 9999.9999 . Units conversion is done by multiplying the analog input value by the quotient of the range divided by 4095 times 10,000 and then adding any offset to that product. For example, if a thermocouple is reading 2048 counts and has a range of 50 to 1760 degrees $C$, the calculation would be done as follows:

$$
\begin{aligned}
& \text { Multiplier }=(\text { Range } / 4095) * 10,000=((1760-50) / 4095) * 10,000 \sim 4176 \\
& \text { Offset }=50 \\
& \text { Intermediate }=\text { Input } * \text { Multiplier }=2048 * 4176=\text { Reg. } 1.855 \\
& \text { Reg. } 2.2448
\end{aligned}
$$

$$
\text { Engineering units }=\text { Intermediate Reg. } 1 .+ \text { Offset }=855+50=905 \text { Degrees } \mathrm{C} \text {. }
$$

Since the Modicon is not capable of floating point math, the content of register 2 is discarded. The multiplier is calculated and coded as a constant in the ladder logic. Therefore, the calculation shown above is accomplished with a simple multiply block followed by an add block.

\section{Watchdog Timer}

The watchdog timer (WDT) was implemented to insure that an interlock would occur if the Modicon locked up. Having the Modicon toggle a discrete output at a regular interval does this. If the toggle stops for more than a few seconds the emergency shutdown cabinet asserts the interlock. The WDT uses two timers to produce a repeating output of five seconds on followed by one second off.

The inverted output of a five-second timer provides the output of the WDT. The noninverted output is used to power a one-second timer. The non-inverted output of the one- 
second timer is used to reset the five-second timer. In normal operation the inverted output of the five-second timer stays on until the timer reaches completion. At that time the non-inverted output turns on, powering the one-second timer. When the one-second timer completes its cycle, its non-inverting output resets the five-second timer and the cycle starts again. The WDT uses a second discrete output to power the time delay relays used in the emergency shutdown cabinet. This output stays on continuously.

\section{Control Thermocouple Selection}

The Modicon works in conjunction with the Factory Link system to select the thermocouple or other temperature measurement device that will be used as the basis for control of the melter temperature. There are four thermocouples and one optical pyrometer that can be selected (TT1A - TT1E). The Factory Link system accepts input from the operator and then asserts the coil that represents the selected temperature device. Only one device may be selected at any one time. The Modicon uses the selected coil to identify which temperature device feeds the melter temperature control loop.

\section{Delta Temperature Alarm}

The delta-temperature alarm is used to identify when a large temperature difference exists between the control temperature device and the remaining thermocouples. The setpoint for the delta-temperature alarm is provided by the Factory Link system. Upper and lower limits are calculated by adding and subtracting the setpoint from the current control device reading. Each thermocouple reading is then compared to the upper and lower limits. If any of the thermocouple readings fall outside of the allowable limits for more than ten seconds the delta-temperature alarm is asserted.

\section{PID Control}

The Modicon provides melter temperature control using a standard PID algorithm. The input from the control temperature device is copied to the PID process variable input. The PID output is copied to the XP20 field analog output register (40001). Automatic/manual PID control is selected from the Factory Link system. If the system interlocks at any time during PID control, the melter temperature control loop is placed in manual, the output is set to 0 , and the setpoint is set to 0 .

\section{Pour Tip Cooling Air Control}

The pour tip cooling air solenoid valves are controlled from the Factory Link system. Factory Link asserts two coils in the Modicon that provide power to each of the solenoid coils. The system interlock is also a permissive to the solenoid valves to insure the cooling air is turned on in the event of an interlock. This insures that the melter cannot pour during an interlock. 


\section{System Interlock}

The system interlock uses networks $72-75$ to identify any interlock conditions that exist. These interlock conditions are divided into three zones: melter, pour tip, and support services: Interlock conditions are identified in Appendix 1. Valid interlocks must be present for at least two seconds before the interlock is asserted. This is done to reduce nuisance interlocks.

The interlock is a normally energized discrete output that goes to the emergency shutdown cabinet. The interlock must be normally energized to insure that an interlock will be asserted even if the power to the control system has been interrupted.

\section{$\underline{\text { Trapping Alarms and Interlocks }}$}

The largest part of the Modicon ladder logic consists of alarm and interlock trapping. Setpoints for all alarms and interlocks are provided by the Factory Link system. Alarms and interlocks identified in Appendix 1 are handled in largely the same way. The current value for a process instrument is compared to the alarm and interlock setpoints. If the process variable exceeds its alarm or interlock setpoint for more than one second, it is considered valid. Valid alarms are asserted immediately and handled by the alarm tracking networks. System interlocks require an additional two-second delay that is handled by the system interlock network.

If an alarm is asserted, it will remain asserted until the process variable is less than the alarm setpoint minus the alarm deadband. This is to reduce nuisance alarms.

When a process variable goes above $20 \mathrm{~mA}$ or below $4 \mathrm{~mA}$, the Modicon reads a negative number. This error condition is trapped for temperature devices as an interlock.

\section{$\underline{\text { Alarm Tracking and Activation }}$}

Alarms are displayed in three places: the Factory Link system, the emergency shutdown cabinet, and the control room. The Modicon is responsible for triggering alarm displays in the emergency shutdown cabinet and in the control room. Each alarm must initiate the audio alarm even if another alarm is active and has been acknowledged. In order to accomplish this in the control room, when a new alarm is received the existing alarm must be reset momentarily and the new alarm asserted.

The main feature of the alarm tracking system is the alarm tracking register. Each time a valid alarm condition is identified, the alarm tracking register is incremented by 1 . Each time an alarm condition clears, the alarm tracking register is decremented by one. Each scan, the alarm tracking register is compared to its value during the previous scan. If the current value is greater than the previous value, the alarm coil is dropped for one second and then reasserted. This action clears the enunciator panel and then reasserts the alarm, 
requiring the operator to acknowledge the new alarm. When the alarm tracking register contains a 0 , there are no active alarms.

The control room enunciator panel requires a normally energized coil for both alarm and interlock conditions. In this configuration, the alarm and interlock are indicated even in the event of power loss in the field.

\section{Data Acquisition Watchdog Timer}

A watchdog timer for the data acquisition system was established to insure the operator knows when the data acquisition is not running. In this case the Modicon is watching a coil that is toggled by the data acquisition system. If the toggle stops for more than five minutes, the Modicon asserts a coil that informs the Factory Link system that the data acquisition system in not running. This information is in turn displayed on the operator console. 


\section{Appendix 1.}

Figure 1.

Data and Control Flow Diagram of the CIM Control System

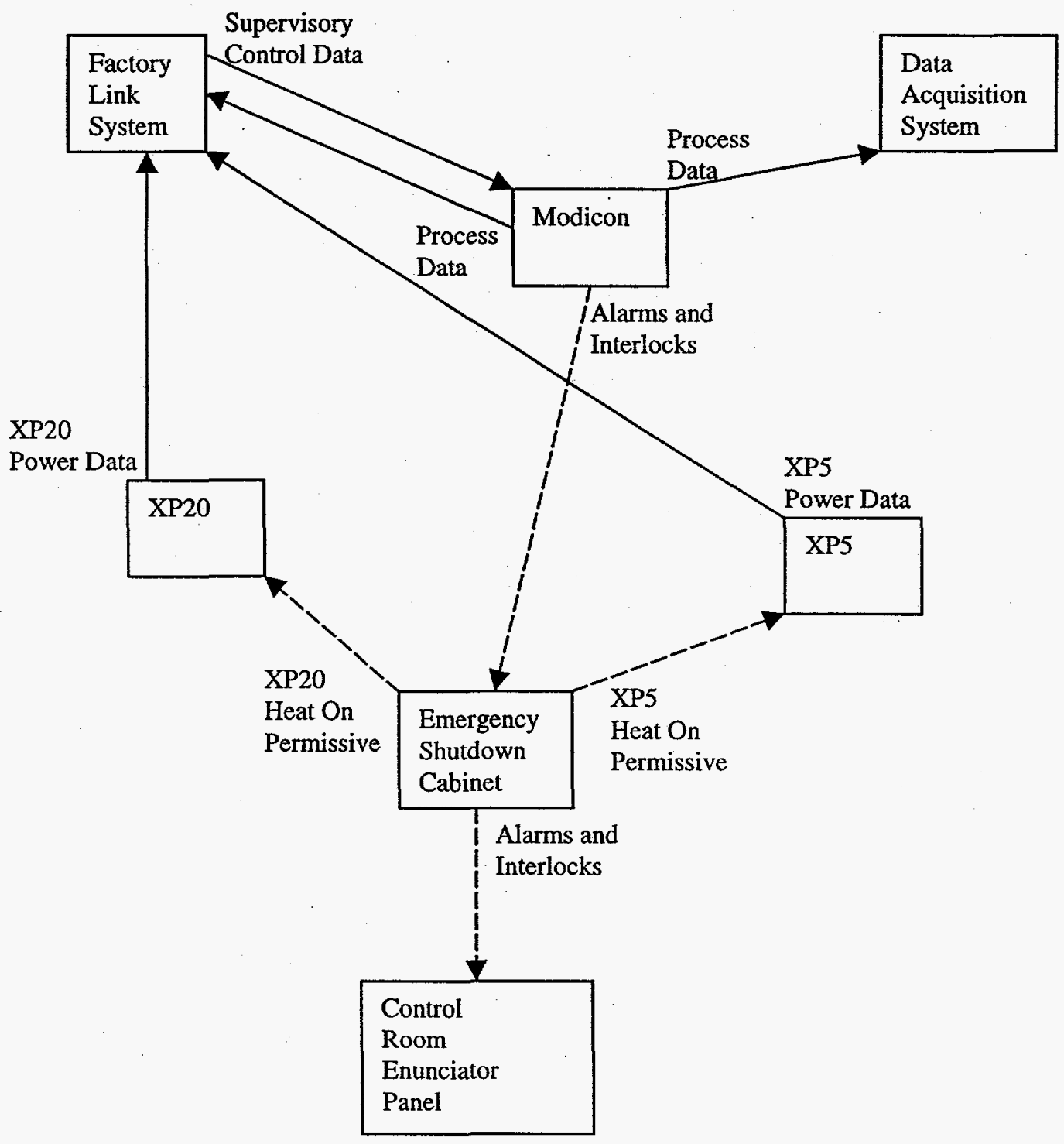


Appendix 2.

Alarm and Interlock Summary

Description

Delta Temperature

TT1E Melter Temperature

TT1A Melter Temperature

TT1B Melter Temperature

TT1C Melter Temperature

TT1D Melter Temperature

TT2A Pour Tip Temperature

TT2B Pour Tip Temperature

TT2C Pour Tip Temperature

TT2D Pour Tip Temperature

FSL62 Cooling Water Flow

FSL63 Cooling Water Flow

TT4 Cooling Water Temperature

TT7 Cooling Water Temperature

PDI81 Offgas pressure

24 VDC Monitor

FT82 Offgas Flow

PDI83 HEPA DP
Alarm?

Yes

Yes

Yes

Yes

Yes

Yes

Yes

Yes

Yes

Yes

Yes

Yes

Yes

Yes

Yes

Yes

Yes

Yes
Interlock? Interlock Zone

none

Melter

Melter

Melter

Melter

Melter

Pour Tip

Pour Tip

Pour Tip

Pour Tip

Other

Other

Other

Other

Other

Other

Other

Other 